\title{
Inteligência Artificial e a Crise do Poder Judiciário: Linhas \\ Introdutórias sobre a Experiência Norte-Americana, Brasileira e sua Aplicação no Direito Brasileiro
}

\author{
Artificial Intelligence and the Judiciary Crisis: Introductory Lines on the
}

North American, Brazilian Experience and its Application in Brazilian Law

Recebimento em 05/08/2020

Thiago Souza Brito
Rodrigo Saldanha Fernandes $^{2}$

Aceito em 02/09/2020

Resumo

O presente artigo tem como objetivo analisar a denominada crise no Poder Judiciário brasileiro, que demanda novas formas de enfrentar antigos problemas. Dentre as medidas possíveis, propõese a utilização de novas tecnologias. Desta forma, o presente artigo busca analisar as possíveis aplicações da Inteligência Artificial pelo Judiciário. Para tanto, são explicitados alguns problemas vivenciados pelo jurisdicionado no Brasil. Apresenta também conceitos introdutórios sobre inteligência artificial e sua aplicabilidade nos EUA e no Poder Judiciário brasileiro. Por fim, demonstra algumas hipóteses de ampliação da utilização da IA no contexto brasileiro.

Palavras-chave: Direito Processual. Inteligência Artificial. Juiz-Robô.

\begin{abstract}
This article aims to analyze the so-called crisis in the Brazilian Judiciary, which demands new ways of facing old problems. Among the possible measures, the use of new technologies is proposed. Thus, the present article seeks to analyze the possible applications of Artificial Intelligence by the Judiciary. Therefore, some problems experienced by the jurisdiction in Brazil are explained. It also introduces introductory concepts about artificial intelligence and its applicability in the USA and the Brazilian Judiciary. Finally, it demonstrates some hypotheses of expanding the use of AI in the Brazilian context.
\end{abstract}

Keywords: Procedural law. Artificial Intelligence. Judge-Robot.

\section{Introdução}

Isaac Asimov, em dezembro de 1983, foi convidado por jornalistas a prever como seria o mundo em 2019. Foram 35 previsões no total, publicadas no Jornal The Toronto Star.

\footnotetext{
${ }^{1}$ Doutor e Mestre em Direito Processual Civil pela FDUFMG. Membro do Instituto Brasileiro de Direito Processual - IBDP. Membro fundador do Instituto de Direito Processual - IDPro. Professor de Processo Civil da Universidade do Vale do Rio dos Sinos - UNISINOS e do Centro Universitário Fadergs. Advogado.

${ }^{2}$ Bacharel em Direito pelo Centro Universitário Fadergs.
} 
Dentre elas, antecipouque, no âmbito da informática, robôs estariam inseridos em todos os setores da sociedade, chegando até na casa das pessoas. E foi além, ao antever as consequências da substituição do homem por máquinas nas mais diversas atividades laborais. Nisto, sem dúvidas, estava correto.Atualmente, temos robôs que realizam cirurgias médicas, pilotam aviões, investem em ações, etc.. Se a expansão da robótica não parece encontrar limites, cumpre indagar como o Poder Judiciário pode se valer dos avanços tecnológicos para aprimorar a prestação jurisdicional, sem violar garantias constitucionais.

O presente artigotem como objetivo apresentar os conceitos básicos relativos àinteligência artificial (IA) e as possíveis contribuições para oenfrentamento da "crise" no Poder Judiciário.Para tanto, serão explorados elementos que obstaculizam a prestação jurisdicional tempestiva. Em seguida, apresenta-se os conceitos básicos que envolvem a temática da IA, continuadode exemplificação dos modelos implementados nos EUA e no Brasil. Sustenta-se, ao final, que a sua utilização pode ser potencializada, desde que sejam estabelecidosmecanismos de padronização, governança e fiscalização, para evitar violações aos dispositivos da Constituição Federal de 1988.

\section{A Crise do Poder Judiciário}

Sobre a "Crise do Poder Judiciário", compreendida enquanto o excesso de ações pendentes de julgamento e demora na prestação jurisdicional, parece não existir discordância na literatura especializada. $\mathrm{O}$ estoque de processos que aguardam julgamento, somados ao número crescente de novas demandas, causa a insatisfação da sociedade com os serviços judiciais. A solução outrora proposta, que pressupõe o aumento das estruturas para suportar o incremento delitígios, em um contexto de crise econômica, não mais se sustenta. Outras soluções precisam ser encontradas.

Não se mostra viável esgotar neste trabalho todas as dimensões e facetas do tema. Porém, para os fins propostos, elencaremos três problemas da mencionada crise, para posterior relação com as possibilidades advindas da IA no Poder Judiciário.

O primeiro, e mais notório, consubstancia-seno quantitativo de processos em tramitação. O Brasil, com seus 92 tribunais, possui o maior sistema Judiciário do mundo (D’ALMEIDA et. al, 2020, p. 8). De acordo com orelatório“Justiça em Números 2019” do Conselho Nacional de Justiça (CNJ), tramitam 78,7milhões de processos em todos os órgãos que compõem o Poder Judiciário. 
O crescimento acumulado no período $2009-2018$ foi de $29,6 \%$, ou seja, acréscimo de 18milhões de ações, mesmo considerando uma leve redução (-1,13\%) se comparado 2017 e 2018(CNJ, 2019, p.79).O ano de 2018 foi o que apresentou o melhor resultado em relação aos processos baixados, uma vez que 31,9milhõesforamarquivados, contra 28,1 milhões ingressantes, representando 13,5\% de evolução.Em contrapartida, o cenáriohistórico desde 2009 é desfavorável, registrando um crescimento acumulado de 14,2\% em relação a processos novos. Desde 2015 percebe-se que o número de baixados supera os de casos novos, sendo que, ainda segundo o CNJ (2019, p.80),em 2017 mais de 30 milhões de casos foram solucionados.Vale aqui a ressalva, por sua importância, de que a diminuição do estoque de processos em julgamento se deveu à reforma trabalhista ocorrida no ano de 2017, que causou significativo impacto no número de ações propostas.

Mesmo considerando esta melhora a partir de 2015, não é possível afirmar que foi encontrada a solução definitiva para a demora na prestação jurisdicional. Muito pelo contrário. A percepção da ineficiência jurisdicional e insatisfação do jurisdicionado é crescente. Ainda segundo o CNJ, "mesmo que não houvesse ingresso de novas demandas, e fosse mantida a produtividade dos magistrados e dos servidores, seriam necessários aproximadamente 2 anos e 6 meses de trabalho para zerar o estoque"(CNJ, 2019, p.80).

O significativo aumento do número de processostem como origem remotao amplo acesso à justiça assegurado pela $\mathrm{CF} / 88$. Anteriormente, valiam-se da jurisdição somente aqueles que detinham capacidade econômicasuficiente para pagar as taxas judiciárias, encargos de auxiliares da justiça e advogados particulares (CAPPELLETTI e GARTH, 2002, p. 4-5). Com o novo texto constitucional, o acesso à justiça foi amplamente assegurado, colocando o Poder Judiciário com a função de solucionar os mais diversos conflitos na sociedade. Ressalte-se, por oportuno, não ser o acesso à justiça, por si só, um fator negativo.Como já sustentado, deve-se comemorar esta conquista democrática, uma vez que possibilitou à toda população principalmente as classes sociais menos favorecidas - um canal para solução dos seus litígios (BRITO, 2013, p. 17). Portanto, qualquer soluçãoconstitucionalmente válidapara o excesso de processos não passa pela redução do acesso à justiça. Deve-se encontrar uma forma de solucionar os litígios, não os afastar do Poder Judiciário.

Em segundo lugar, destaca-se o custo do aparato judiciário. Para receber tantos processos, o Poder Judiciário despende, anualmente, elevada quantia do eráriopara o seu funcionamento e manutenção. De acordo com o CNJ, as despesas totais do Poder Judiciário atingiram o montante de $\mathrm{R} \$ 93,7$ bilhões, sendo que $\mathrm{R} \$ 85,1$ bilhões são destinados ao pagamento de pessoal, o que representa $90,8 \%$ do orçamento. Importante aqui ressaltar que a 
fonte de tais quantias são os tributos pagos pelo cidadão brasileiro, uma vez que somente 11,61\% da despesa total provem do pagamento de taxas e emolumentos daqueles que efetivamente se utilizam do Poder Judiciário (WOLKART, 2018, p. 84-85).

Sobre o tema, importante o destaque que o montante totaldo orçamento teve um crescimento de $3,6 \%$ quando confrontado ao ano de 2016 , e equivale a $1,4 \%$ de todas as riquezas produzidas pelo Brasil naquele ano, considerando, para tanto, o Produto Interno Bruto (PIB).Para situar a dimensão do problema,ao comparar com outros países do mundo,partindo de números do ano de 2013,Luciano da $\operatorname{Ros}(2015$, p.3) demonstrou que na Alemanha a manutenção do Poder Judiciário consome o equivalente a $0,32 \%$ do PIB, enquanto Portugal gasta o percentual 0,28\% Por sua vez, na Inglaterra e nos EUA, $0,14 \%$. Na América do Sul, a Venezuela gasta 0,34\% do PIB com a Justiça, Chile e Colômbia desembolsam pouco mais de $0,2 \%$ e a Argentina, $0,13 \%$, o que apenas evidencia o quão desproporcionalmente caro éa manutenção do Judiciário. A redução de despesas, nas raras oportunidades que ocorre, é resultado do aumento de cargos vagos de magistrados, que atingiuo percentual 0,6\% no ano de $2019(\mathrm{CNJ}, 2019$, p. 73).

Diante disto, deve-se buscar saídas que auxiliem na diminuição de gastos públicos, destacadamente quando se considera que o acesso à justiça disputa recursos do Estado que poderiam ser destinados para outros acessos, como educação, saúde e moradia, igualmente previstos na CF/88 (WOLKART, 2018, p. 31).

Por fim, o terceiro elemento a ser destacadoé o índice de produtividade dos juízes. Ao aprofundarmos a análise dos dados disponibilizados pelo CNJ, é possível identificar que desde de 2014 o índice apresenta uma crescente evolução, atingindo nos últimos 4 anos o percentual de $10,7 \%$ de crescimento, com uma média de 1.877 processos baixadosem 2018, o que representa uma média de 7,5 casos solucionadospor magistrados por dia, considerando dia útil e não abatendo férias e recessos. Trata-se, por certo, de média elevada em comparação com os juízes de outros países do mundo. Entretanto, a produtividade dos magistrados certamente encontrará um limite, uma vez que a capacidade humana de concentração e leitura, por óbvio, não pode se expandir de forma irrestrita.

Diante do exposto, deveria o Poder Judiciário preparar-se para a nova realidade. Contudo, a despeito de todos os esforços, poucasforam as melhorias efetivas para torná-lo mais eficiente. Além disso, há uma certa insistência em propostas que já se mostraram insuficientes, como a criação de microssistema de julgamento de casos repetitivos, reforma legislativa e aumento de cargos. Por isso, ao que tudo indica, a IA surge como saída viável - não como panaceia, é importante ressaltar - para entregar ao cidadãoa prestação jurisdicional tempestiva. 


\section{Inteligência Artificial: Conceito e Machine Learning}

Antes de avançar,é necessário estabelecer alguns conceitos relativos à área de IA. Conforme definição deCoppin(2010),IAconsiste na capacidade de um computador pensar e ter consciênciada mesma forma que o ser humano. Para tanto,utilizaos algoritmos, que são expressões textuais das etapas da decisão de algum problema, que se vale de um conjunto de dados disponibilizados, combinadas com o processamento de hardware das máquinas computacionais. Desta forma, seria possível a criação de sistemas que simulam a capacidade do ser humano de pensar, comportar-se e encontrar soluções para problemas.

Para atingir tais objetivos, ainda que não seja clara a origem da capacidade cognitiva humana, como ela emerge no cérebro, nem mesmo os seus limites, a IA pretende ir além da simples mímica da cognição, mas sim construir agentes inteligentes (RUSSEL, 2013, pág. 25).

As possibilidades de aplicação da IA são vastas, sem encontrar limitações em áreas específicas da atividade humana, tratando-se de tema verdadeiramente multidisciplinar. De pilotos de avião e veículos, médicos, operadores no mercado financeiro, Ecommerce, agricultura, dentre outras, todas as áreas do conhecimento podem se beneficiar da IA. Para tal, vale-se deconhecimento de diversas áreas como ciência da computação, matemática (lógica, otimização, análise, probabilidades, álgebra linear), ciência cognitiva e por fim, o conhecimento específico do campo ao qualserá implementada.

Para os fins do presente trabalho, necessário aprofundar nos subgrupos da IA. Interessa, em especial, osistema de machinelearning,que tem como característica a desnecessidade deprogramação humana das regras que governam uma tarefa, vez que é possível deixar que a máquina aprendasozinha, de forma autônoma, como solucionar o problema(VILLAN, 2018).Nele, a máquinaautomatiza a construção dos modelos analíticos utilizando a exame de dados disponíveis em sua base por meio de algoritmos. Pretende-se que osistema que aprendasozinho, por meio das informações contidas em seu banco de dados, identificando padrões e tomandodecisões com o mínimo de intervenção humana. Para que tenha sucesso, é necessário que os dados inseridos atendam a determinados requisitos estabelecidos pelo programador. Como veremos adiante, tal característica é essencial para o debate sobre a utilização da IA pelo Poder Judiciário.

O machinelearning surgiu da capacidade de os computadores examinarem uma extensa base de dados. Quanto maior essa base, maior assertividade terá a ferramenta. Os algoritmos de machinelearningpossuema aptidão de assimilação a partir dos dados a eles submetidos e, assim, aprendem a executar diferentes tarefas de forma autônoma. Logo, ao serem 
expostos a novos dados, eles se adaptam a partir dasoperaçõesanteriores e os padrões se moldam para oferecer respostas confiáveis às novas informações.

Como omachinelearning utiliza de uma abordagem iterativa (realiza o procedimento inúmeras vezes) para aprender com os dados, o conhecimento pode ser facilmente automatizado. As etapas são executadas repetidas vezes até que um padrão robusto e confiável seja encontrado.Desta forma, o software consegue adaptar-se as novas situações(WOLKART, 2019, p. 706). Por isso, possui ele a capacidade de previsão das respostas futuras a problemas ainda não formulados, por intermédio dos padrões aprendidos a partir de dados a ele imputados como forma de treinamento do sistema.

Antes de avançar para as aplicações jurídicas da IA, outros esclarecimentos ainda são necessários.

\section{1 - Algoritmo e Programação de Máquinas}

Compreendido o que se compreende por IA emachinelearning, é necessário esclarecer como se vale de algoritmos para encontrar a solução para os problemas propostos. Algoritmo, segundo a clássica definição de Alan Mathison Turing, é umconjunto não ambíguo de instruções simples e precisas, quesão descritas com um número finito de códigos.Como apontam Dierle Nunes e Ana Luiza Marques (2018, p. 424),“A inteligência artificial funciona a partir de sistemas de dados programados para darrespostas conforme a base de dados disponível. Esses sistemas recebem o nome dealgoritmos." Desta forma, o algoritmo exige que os passos programados sejam bem definidos para uma execução assertiva, evitando ambiguidades. Caso contrário, o algoritmo realizará a tarefa de forma diversa do esperado pelo programador.

Os algoritmos podem ser de duas espécies, a saber, programados e não programados. Como bem simplificam Isabela Ferrari, Daniel Becker e Eric Wolkart (2018),“(a)lgoritmos programados seguem as operações ('o caminho') definidas pelo programador. Assim, a informação 'entra' no sistema, o algoritmo faz o que está programado para fazer com ela, e o resultado (output) ‘sai’ do sistema.” Já os algoritmos não programados têm como características serem produzidos por outro algoritmo. Neste caso, o próprio computador faria a sua programação, por meio da inserção de dados e a resposta desejada (input) e tendo como resultado um novo algoritmo (output).

Partindo de tais premissas, pode parecer que a resposta ao problema apresentada pelo algoritmo seria neutra, sem influência de fatores externos. Seria a resposta mais adequada à questão, isenta e imparcial. Aqui reside, todavia, um dos maiores problemas da utilização da IA. 
$\mathrm{Na}$ realidade, a decisão por algoritmos pode gerar resultados que são incorretos ou mesmo injustos. Isabela Ferrari, Daniel Becker e Eric Wolkart (2018) identificaram três problemas: “(i) o emprego de data sets viciados; (ii) a opacidade dos algoritmos não programados; (iii) a discriminação que pode ser gerada por algoritmos de machinelearning".

Data sets viciadossão decorrentes de uma base de dados de qualidade científica questionável, ou mesmo incompleta, para alimentar o algoritmo. Aqui não há um problema na programação, mas sim nas informações que são disponibilizadas para o sistema de IA. A escolha da base de dados para treinamento do algoritmo poderá torná-lo enviesado, já que toda a sua estrutura de comportamento em relação aos passos a serem realizados utilizar-se-á destas informações. Para exemplificar, em 2015 o sistema do Google de fotos apresentou um retorno equivocado na categorização de um homem negro. Ele foi identificado como um gorila, tendo sido mais tarde descoberto que o algoritmo não distinguia a pele negra dos seres humanos de animais como gorilas e chimpanzés.Tal fato suscitou dúvidas sobre o banco de dados da gigante de internet, transparecendo que sua base era composta predominantemente de pessoas de cor branca.

Maior problema existe com relação à opacidade dos algoritmos. Conforme esclarecem Isabela Ferrari, Daniel Becker e Eric Wolkart (2018), pela "complexidade de sua operação, a mera observação do output por um ser humano -ainda que seu próprio programador - dificilmente poderia conduzir a alguma conclusãosobre os processos internos que conduziram os inputs até lá, tornando o algoritmo umaverdadeira caixa-preta". Ao desenvolver o algoritmo, o programador escolhe as informações que servirão de input, enquanto selecionam aquelas que serão desconsideradas. Por óbvio, é de se esperar que as informações desconsideradas não sejam de fato relevantes para o resultado que se espera encontrar. Todavia, existe o risco de serem“ignoradas informações importantes para correta análise dasituação, influenciando negativamente nas respostas dadas pelo sistema." (NUNES e MARQUES, 2018, p. 424).

Ao receber os inputs, resultado das escolhas feitas pelo programador, os algoritmos não-programados fazem operações que são desconhecidas de seu programador, uma vez quesão utilizadas regras, informações e análises probabilísticas além da capacidade humana de compreensão. Ou seja, existem pontos cegos dos algoritmos que não devem ser desconsiderados quando se está diante da resposta apresentada.

Por fim, existe a discriminação do algoritmo. Ainda que não esteja escrito de forma explícita no seu código, o viés inconsciente do programador refletirá discriminações de ordem social, de gênero ou cor de pele, e reverberam no resultado encontrado, tornando-o aparentemente "científico". Assim, caso não seja tal característica considerada, as decisões 
resultantes da utilização do algoritmo apenas perpetuarão situações de discriminação, injustiça social ou violência de gênero, etnia ou religião. Tal situação não configura, por si só, um problema de programação ou de base de dados. Com isso, pode surgir o viés algoritmo, que ocorre no momento no qual "as máquinas se comportam de modos que refletem os valores humanos implícitos envolvidos na programação" (NUNES e MARQUES, 2018, p. 425).

Esclarecidos tais conceitos básicos, às vezes de difícil compreensão para aqueles que não estão familiarizados com a temática, as aplicações para o Direito e o Poder Judiciário são inúmeras, como será explicitado no presente trabalho.

\section{Primeiros Passos da IA no Direito: Experiência dos EUA e dos Tribunais Brasileiros}

As implicações da utilização da IA pelo Direito são diversas e profundas. O movimento é por demais complexo para ser considerada uma simples atualização das ferramentas disponíveis aos juristas, ao ponto de autores como Dierle Nunes(2018, p. 426) defenderem estamos diante de um momento denominado virada tecnológica. Para melhor compreende-la, alguns exemplos podem auxiliar na sua compreensão.

\section{1 - IA no Direito Norte-Americano}

Os EUA utilizama IA para auxílio na atividade policial e judiciária, por meio de dados armazenados (big data) em diversas bases. Pretendem, com isso, um policiamento efetivo nos locais mais perigosos e desarticularorganizações criminosas. Ademais, a IA está presente na execução penal para a análise da concessão de benefícios, como a progressão de regime e a liberdade provisória(CARVALHO, 2018).

Nestediapasão, economistas, em parceria com cientistas da computaçãoda National Bureau ofEconomicResearchdos EUA,desenvolveram um software capazde medir a probabilidade de os réus fugirem ou cometerem novos crimes enquanto aguardavam o julgamento em liberdade. Para esta análise o algoritmo atribui uma nota de risco baseadonas informações do caso concreto (qual o tipo de crime, local onde ocorreu e quando a pessoa foi detida), do histórico criminal e da idade do acusado. O programa foi elaboradocom informações de centenas de milhares de decisões da Corte de Justiça de Nova Yorke, posteriormente,validado em outras centenas de milhares de novos casos, tendo sidomais eficiente em relação à análise dos riscosdecorrentes da soltura do que os próprios juízes humanos.Com base nestes resultados, os pesquisadores entenderam que se o software fosse utilizado para auxiliar os juízes em suas 
decisões, seria possível reduzir em $25 \%$ os crimes em Nova York e, consequentemente, reduzir em 40\%os presos provisórios aguardando julgamento (PORTO JÚNIOR, 2017).

Entretanto, algumas cidades dos Estados Unidosjásuperaram a fase de testes eutilizamdo sistema de IA para auxiliar os tribunais, como é o caso deNova Orleans, no estado de Luisiana. Nela, o software desenvolvido possui a capacidade de identificar potenciais criminosos, por meio de dados existentes nas redes sociais, para definiro perfil dos acusados.Contudo, ainda no início das atividades, foram encontrados problemas no método e base de dados escolhidos, uma vez que o resultado, em diversos casos, foi contrário ao desejado. Isso porque se na rede social escolhida não houver indícios de um crime cometido, logofaltarão evidências concretas de eventual inclinação para criminalidade, impossibilitando a aplicação da ferramenta(CARVALHO, 2018).

Assim como em Nova Orleans, outro caso conhecido - e controverso - é o do estado de Wisconsin, que se vale da IA para cálculo de pena de prisão ou para concessão de liberdade provisória.Aqui,os magistrados da área criminal utilizam-se de um sistema privado de pontuação algorítmicamatemática que é calculado com base nas respostas dadas pelo acusado no questionário de periculosidade. O sistema, denominado COMPAS (CorretionalOffenderManagement Profilingfor AlternativeSanctions), foi duramente criticado, pois dentre as perguntas constantes haviam algumas como: "alguém da sua família já foi preso?" Ou “é aceitável que alguém que passe fome roube?” (CARVALHO, 2018).

O COMPAS ganhou notoriedade em razão do julgamento de EricLoomis, condenado a seis anos de prisão por furtar um veículo, evadir do local e se envolver em uma troca de tiros. O software foi utilizado pelo juiz para definir o patamar da pena. O Sr. Loomislevou a questão à Suprema Corte de Winsconsin, uma vez que os critérios utilizados para estabelecer a sua pena eram desconhecidos. A empresa responsável pelo desenvolvimento do sistema não disponibilizou os códigos do algoritmo, por entender que ofenderia o segredo industrial. Assim, o réu foi impedido de realizar a defesa adequada, uma vez que desconhecia os critérios do software para classificá-lo como potencial reincidente. A despeito disso, o Tribunal entendeu que o magistrado humano validou a decisão do software e chegou à mesma conclusão por meio da verificação do crime e dos antecedentes do réu (FERRARI; BECKER; WOLKART, 2018, p. 637).

Para além das aplicações no âmbito criminal, verificam-se outras formas situações nas quais a IA foi testada. Com vistas aidentificar o rigor da ferramenta de IA, aSuprema Corte Americana realizou testes na tentativa de prever suas decisões em determinados processos submetidos à Corte, empregando como material de suporte do robô as decisões anteriores de 


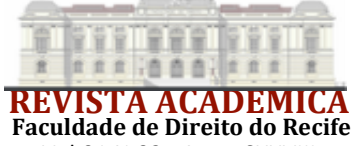

Vol

matérias específicas(CARVALHO, 2018). Surpreendentemente,nos testes executados,a margem de acerto atingiu 75\% em relação aos votos dos juízes humanos.

Outro serviço importante de IA foi desenvolvido por Colin Rule,denominado de MODRIA. Osistema foi idealizado a partir do eBay etem a funcionalidade de buscar a auto composiçãocom o mínimo de interação humana na negociação. Inicialmente o MODRIA procura reduzir a falhas de simetria das informações de cada uma das partes. Pela plataforma as partes conseguem inserir vídeos e fotos, bem como alegações escritas em formato de texto. Se, na primeira oportunidade não acontecer o acordo, o sistema interpreta esta situação e inicia o módulo negociação. $\mathrm{O}$ algoritmo procura nos dados disponíveis, de forma contínua, os pontos de acordo e sugere possíveis soluções para lide. Persistindo o conflito, a plataforma aplica o método de mediação, que atua por meio de intervenção humana, porém totalmente online. Contudo, se por este método o conflito não for solucionado, ocorrerá o último passo que será a aplicação da arbitragem, quando um terceiro imparcial decidirá o caso. O MODRIA já é utilizado para mediar litígios ligados à propriedade intelectual e industrial. Para tanto, o sistema utiliza o big data gerado para refinar os resultados e aumentar as possibilidades de acordos nas futuras transações. Recentemente a Associação Americana de Arbitragem escolheu o MODRIA para elaborarum sistema de ODR - Online Dispute Resolution - que seja capaz de solucionar os conflitos que envolvem seguradoras na cidade de Nova Iorque(WOLKART, 2019, pág.730).

\section{2 -IA e os Tribunais Brasileiros}

Como era de se esperar, cientes das experiências estrangeiras, alguns Tribunais brasileiros se valem de IA para auxílio na triagem de processos e julgamentos. Ainda estão eles distantes do grau de evolução verificada na experiência americana, limitados à fase de digitalização dos processos e mineração de dados. Não obstante, os primeiros passos foram dados. Dentre eles destacam-se o Tribunal Superior do Trabalho (TST), Superior Tribunal de Justiça (STJ) e o Supremo Tribunal Federal (STF), sendo apresentados de forma sucinta a seguir.Em razão de sua relevância, também será explicitada a experiência do Tribunal de Contas da União (TCU), apesar de não integrar o Poder Judiciário. Ressalte-se, por oportuno, que diversos Tribunais de Justiça(D’ALMEIDA et. al, 2020, p. 13-14), como os dos Estados do Acre, Alagoas, Minas Gerais, Pernambuco, Rio Grande do Norte e Rondônia, desenvolveram a sua própria ferramenta. Em razão do escopo e extensão do presente trabalho, não será possível discuti-los. 
Antes de mais nada, é importante ressaltar que a experiência judiciária brasileira com IA tem como premissa a sistemática digitalização dos processos. Segundo os dados disponibilizados pelo CNJ, nosúltimos 10 anos foram ajuizadas 108,3 milhões de novas ações pela via eletrônica. O percentual de adesão ao processo eletrônico considerando todas as esferas atinge 83,8\% dos casos novos (CNJ, 2019, p.95). Este resultado possui extrema relevância quando tratarmos de IA, destacadamente porque, quanto maior o volume de informações disponíveis no banco de dados, melhor será a assertividade do robô nas análises e correlações.

Feita tal ressalva, desde 2016, o TCU utiliza de três robôs para exame de licitações e identificação de fraudes nestes processos. Denominados de Alice (acrônimo Análise de Licitações e Editais), Sofia (abreviatura para Sistema de Orientação sobre Fatos e Indícios para o Auditor) e Mônica (a abreviação de Monitoramento Integrado para Controle de Aquisições), ${ }^{3}$ estes três robôs fazem parte da Labcontas, laboratório de informações de controle, que utiliza ferramentas com machinelearning para automatização na interpretação de documentos e tem como finalidade a classificação e extração automática dos dados que não se encontram estruturados (TAURION, 2016). A intenção da utilização da IA pelo TCU é analisar de forma eficaz as contas, realizando comparações e correlações em milhões de documentos muito rapidamente, de forma mais precisado que se fosse realizado por humanos, menos eficientes quando lidam com grandes volumes de informações.

Por sua vez, em outubro de 2018 o TST adotou o uso da IA para auxiliar nas demandas e tornar mais célere os processos. Por meio de seu sistema denominado Bem-te-Vi, o órgão conseguiu aplicar a IA para analisar a tempestividade dos processos de forma automática. Segundo o Tribunal, cerca de $3 \%$ dos processos são intempestivos e para sua conferência demandavam o emprego de servidores, com gasto de tempo e recursos financeiros. O sistema Bem-te-Vi possui integração com outros sistemas da justiça, como o eRecurso, o PJE e o DEJT, de forma que coleta as informações e realiza os cruzamentos de dados necessários para encontrar a solução. Com o sistema, pretende-se automatizar a verificação da intempestividade, alertando o serventuário responsável, por meio de cores, sobre a sua ocorrência (TST, 2019).

O projeto obteve tanto sucesso que o TST já trabalha para disponibilizar outras funcionalidades para a ferramenta. A expectativa é que o software consiga incluir alertas para

\footnotetext{
${ }^{3}$ Robôs e assistentes virtuais recebem, com muita frequência, nomes femininos, sendo que alguns possuem inclusive vozes nesse gênero, indicando que também no mundo virtual a dominação masculina (BOURDIEU, 2014, p. 21) se perpetua. É o caso da assistente do sistema operacional Windows, chamada Cortana; da Siri, no caso da Apple; e da Alexa, da Amazon. A editora da revista The Atlantic, Adrienne Lafrance, explica que estamos socialmente condicionados a acreditar que funções administrativas e burocráticas (como a de secretária) sejam desempenhadas por mulheres. Logo, os desenvolvedores dos softwares também sãoinfluenciados por essa expectativa, lembrando que em sua maioria, esses desenvolvedores são do sexo masculino (DOMINGOS DE LIMA, 2018).
} 
indicar os impedimentos dos ministros no julgamento de determinados processos, funcionalidade que já se encontra em fase de testes (TST, 2019). De acordo com as informações do próprio tribunal, o sistema possui em sua base mais de dois mil impedimentos cadastrados.

O STJ também possui a sua ferramenta de IA, implementada em duas fases e denominada SOCRATES.O programa tem como finalidade, na primeira fase, automatizar a análise do recurso interposto pela parte e o acórdão recorrido, mediante a seleção da legislação incidente sobre o caso. No segundo momento, haverá a identificação de decisões semelhantes e sugestão de fundamentação para o ministro relator. Importante ressaltar que a validação da decisão ainda permanece com o magistrado competente.

Por sua vez, no STF foi criado o VICTOR ${ }^{4}$, com um custo de desenvolvimento no importe de 1,6 milhão de reais e que foidesenvolvido em parceria com a Universidade de Brasília (UnB). O VICTOR tem a capacidade de analisar os casos de repercussão geral, prometendo decidir aproximadamente dez mil processos e remetê-los às instâncias inferiores. Nele, foi previstoa capacidade de apreciar automática e autonomamente os recursos extraordinários, vez que lhe foram imputados vinte e sete temas de repercussão geral como base de conhecimento e,por intermédio deles, são realizados os cruzamentos com as informações contidas no processo. A devolução para o Tribunal de origem se dá tanto naaplicação de tese já aprovada pelo STF, quanto para as hipóteses de sobrestamento (art. 1.036 do CPC). Esta última entrega da ferramenta está em fase de homologação, mas já encontra uma média de acerto de aproximadamente 90\%(TEIXEIRA, 2018).

Atualmente, o VICTOR identifica e separação das principais peças do processo: acórdão recorrido, decisão de admissibilidade, a sentença, o agravo no recurso e a petição do recurso extraordinário. Apenas para esta função era despendido um tempo aproximado de 30 minutos por processo pelos serventuários.O VICTOR realiza a função em apenas 5 segundos. Para realizar tal atividade, o sistema converte textos que foram recebidos no formato de foto, para um formato de texto padrão, para permitir a transcrição de trechos sem a necessidade de despender um servidor na digitação(TEIXEIRA, 2018).

Assim, o desempenho do VICTOR é de enorme valia para o Poder Judiciário, pois a identificação e organização de processos idênticosatende a necessidade de uniformização e estabilidade prevista no art. 926 do CPC 2015. Evita-se assim, o tratamento diferenciado em

${ }^{4}$ Diferentemente da tendência de nomenclatura para assistentes virtuais com o gênero feminino, o sistema do STF denominado VICTOR é uma homenagem a VICTOR NUNES LEAL, ministro do STF de 1960 a 1969. Ele foi o principal responsável pela sistematização da jurisprudência do STF em súmulas, o que facilitou a sua aplicação nos recursos(TEIXEIRA, 2018). 
casos iguais, respeitando as diferenças relevantes, sob pena de violar direitos individuais(FORSTER, 2018).

Interessante aqui destacar que o STF já recuperou o recurso investidono desenvolvimento do VICTOR e possibilitou mais retornos financeiros à corte. Somente no primeiro semestre de 2018 foram recepcionados 42 mil processos e eles exigiriam aproximadamente 22 mil horas de trabalho dos servidores para separar e identificar as peças principais, organizando toda a documentação. Caso tais tarefas fossem executadas manualmente pelos servidores, despenderiam dois anos e meio, ao custo aproximado de três milhões de reais(TEIXEIRA, 2018).O STF espera que o VICTOR se torne um aliado na tramitação dos feitos e não como forma de substituir os humanos (tanto os servidores quanto os ministros) nas tarefas diárias.

\section{Possibilidades e Limites da IA no Poder Judiciário Brasileiro}

Diante de todo o exposto,parece certo afirmar que a IA auxiliará na resolução de alguns dos problemas que constituem a acima mencionada, ainda que brevemente, "Crise do Poder Judiciário". Cumpre-nos, por conseguinte, questionar a sua aplicabilidade para além daquelas já implementadas pelo Poder Judiciário brasileiro, destacadamente a modificação do arcabouço legislativo e o incremento de investimentos financeiros.

\subsection{Necessidade de Implementação das ODR}

De plano, podemos antever a aplicação da IA na fase da audiência de mediação e conciliação. As formas de resolução alternativa de controvérsia foram definidas pelo legislador como mecanismo para construção das soluções dos litígios. Exatamente por isso restou previsto no art. $3^{\circ}, \S 3^{\circ}$, do $\mathrm{CPC} / 15$, o incentivo à mediação e à conciliação, bem como a ocorrência de uma fase de conciliação obrigatória (art. 334 do $\mathrm{CPC} / 15$ ) antes da contestação. Inclusive, a pandemia do novo Coronavírus (COVID-19), que teve início no ano 2020, evidenciou a necessidade de se buscar saídas diferentes para a continuidade da prestação dos serviços judiciais mesmo com a restrição de contato social.

Entretanto, a despeito de sua importância, as pautas de audiência dos foros estão sobrecarregadas, com previsão de atos para diversos meses, quando não anos, após o ajuizamento da demanda. Por isso, parece uma solução viável a ODR, com investimento em um aplicativo desenvolvido exclusivamente para tal finalidade ou mesmo pelo site do órgão 
julgador, no qual será possível realizar propostas de forma online e entabular o acordo sem a necessidade do ato físico de comparecimento na sede do Foro.

O ODRse vale dos meios adequados de resolução de conflitos já conhecidos, como mediação e conciliação, para permitir a pacificação sem a participação do magistrado. Porém, o faz direcionado para o mundo digital, mais precisamente em plataformas online. Desta forma, ao invés de as partes se encontrarem em um lugar físico para dirimir o conflito, elas se reúnem em salas virtuais e por ali resolvem as controvérsias (LOPES, 2018). Para além de uma simples virtualização dos meios adequados, onde teve a sua origem e ainda possui aplicabilidade, o ODR permite a atuação da tecnologia, sendo ela identificada como a quarta parte envolvida na resolução do caso, além dos litigantes e do mediador (MARQUES, 2019). Por meio dela, é possível instruir as partes sobre os seus direitos e as possíveis consequências de suas decisões, bem como possa "ser utilizada, em especial, para combater tendências humanas consideradas enviesadas, ineficientes, erráticas e precipitadas, também muito comuns no âmbito da resolução de disputas" (MARQUES, 2019), destacadamente dos litigantes habituais. Isso porque a tecnologia permite o agrupamento, análise e seleção de diversos processos ao mesmo tempo, identificando padrões de comportamento abusivos ou pouco cooperativos de determinadas partes, criando soluções adequadas para o caso em apreciação, mas sem perder a perspectiva do seu impacto em um conjunto. Por sua característica, o ODR surge como ferramenta importante para auxiliar o Poder Judiciário a solucionar os litígios, sendo aplicado nos EUA, Noruega, Islândia, Liechtenstein, bem como foi incentivado pela UNCITRAL para arbitrar disputas entre empresas (WOLKART, 2019, p. 731)

O primeiro entrave a ser superado é o financiamento do meio para realização da ODR. O investimento para a implantação da audiência com o mediador/conciliador robô pode ser deduzido da economia que resultará a redução de despesas com pessoal e estrutura física para realização de audiência presencial, sem mencionar a economia de tempo das partes com deslocamento para atos que, em diversas oportunidades, se mostram infrutíferos.

As vantagens advindas de sua adoção certamente superam qualquer entrave.Veja-se o exemplo do Estado da British Columbia, no Canadá, no qual um modelo de ODR foi implantado para permitir que o consumidor, insatisfeito com um produto ou serviço, possa buscar a resolução da controvérsia diretamente com a empresa, por meio de uma mediação online (MARQUES, 2019).Com isso, naquele evita-se que o litígio chegue ao juizado de pequenas causas, poupando os recursos e tempo despendidos em milhares de processos de menor complexidade e simples resolução. 
Caso tal modelo seja adotado pelos Tribunais brasileiros, destacadamente naquelas ações que envolvem os litigantes habituais e causas relativas ao Direito do Consumidor e ao Direito Previdenciário, será possível reduzir os custos para todos os envolvidos. Importa aqui destacar que tal modelo foi adotado pela União Europeia para litígios entre consumidores e fornecedores, bem como alguns estados nos EUA também se valem de método semelhante para os property taxes disputes(WOLKART, p. 730).

Além disso, é possível vislumbrar o aperfeiçoamentoda ferramenta para enfrentar as ações repetitivas e demandas de massa, destacadamente na simplificação dos procedimentos para o mesmo grupo de litigantes frequentes. Uma vez apurado o comportamento pouco cooperativo daqueles que se valem do Poder Judiciário de forma habitual, em situações de violação dos direitos enquanto aguardam a decisão judicial, a ferramenta pode comunicar ao magistrado da existência de um padrão comportamental contrário ao princípio da boa-fé e da cooperação (arts. $5^{\circ}$ e $6^{\circ}$ do $\left.\mathrm{CPC}\right)$. Ou seja, a ferramenta poderá instrumentalizar os juízes humanos ao desincentivara litigância.

Sem se olvidar as ODR também poderão ser desenhadas para identificação de novos temas repetitivos, permitindo ao Poder Judiciário atuar de forma preventiva nos litígios, adotando soluções adequadas aos litígios de massa.Ao receber as demandas, valendo-se de algoritmos programados para identificar situações jurídicas pouco frequentes em determinada região ou comarca, a ferramenta pode avisar, desde logo, aos juízes sobre o problema, permitindo que soluções sejam pensadas de antemão, tais como a comunicação imediata ao Ministério Público para defender eventual interesse coletivo ou as entidades de estrutura especifica (ZANETTI e CABRAL, 2019).

$\mathrm{Na}$ hipótese de a conciliação virtual tornar-se infrutífera, o sistema de IA encaminhará a demanda para a próxima etapa do rito processual, valendo-se da metodologia já aplicada, com sucesso, pelo MODRIA. Contudo, se proveitosa, a plataforma poderá gerar um documento de homologação judicial para assinatura do juiz, encerrando o procedimento, reduzindo os custos e proporcionando maior celeridade processual.

Não se pode esquecer, neste quesito, que a realidade social brasileira é complexa e diversa, de modo que tais elementos devem ser considerados na implantação da ODR. Tendo em vista que considerável percentual da população brasileira não tem acesso à internet ou mesmo a um computador pessoal, esperar que o Poder Judiciário permaneça acessível a todos enquanto espera do jurisdicionado comodidades que ele não dispõe restringe o acesso à justiça constitucionalmente garantido. Por isso, é imprescindível que os Tribunais, ao adotarem tais modelos de audiência, disponibilizem computadores em locais de atendimento, ou mesmo acesso 
à internet em locais específicos, para que possa o jurisdicionado acessar as plataformas de mediação e conciliação. O objetivo permanece sendo, relembre-se, a tutela jurisdicional efetiva.

\section{2 -Despachos e ImpulsosProcessuais pelo Juiz-Robô}

Além disso, é possível vislumbrar, sem maiores entraves, a IA na edição de atos processuais sem cunho decisório.

No curso do processo, o magistradopossui duas funções distintas, a saber, conduzir o processo conforme o procedimento previsto na lei, resolvendo os incidentes até o momento adequado à realização da prestação jurisdicional, bem como dar solução à lide, aplicando o direito material ao caso em litígio. Neste iter, pratica eleatos decisórios e não decisórios. Nos atos decisórios existe um comando do julgador, como nos casos de sentença e decisão interlocutória. Tanto as questões de fato como as de direito poderão ser dirimidas pelas decisões, produzindo efeitos dentro do processo e, algumas vezes, podendo expandir-se para fora dele (THEODORO JUNIOR, 2015, pág. 556).Por sua vez, aqueles atos em que predominam a função administrativa ou de polícia judicial serão denominados não decisórios. No art. 203 do CPC/15 são os despachos elencados como atos não decisórios, ainda que não esgote o mencionado dispositivo todos os atos processuais do juiz (THEODORO JUNIOR, 2015, p. 563)

Com efeito, em diversas oportunidades, o magistrado precisa tomar medidas concretas para que o ato decisório seja cumprido, como nas hipóteses de expedição de alvarás, solicitação de força policial, bloqueio de bens e contas, apreensão de passaporte, bloqueio de carteira nacional de habilitação e cartões de crédito, dentre outras medidas. Ademais, existem aqueles nos quais o juiz terá a função de documentar atos jurídicos, como nos autos de arrematação (art. 903, caput) e de adjudicação (art. 877, § $1^{\circ}$ ), os autos de demarcação (art. 586) e de divisão (art. 597), entre outros.

O CPC 2015 em seu art. 203, §4 $4^{\circ}$, determina que atos meramente ordinatórios devem ser praticados pelas secretarias judiciais, sendo revistos pelo juiz somente quando necessário. Esta mudança serviu para descentralizar algumas atividades do magistrado, de modo que possa ele concentrar tempo e esforços nos atos de maior relevância de sua atividade jurisdicional (THEODORO JÚNIOR, 2015, pág. 560).

$\mathrm{Na}$ prática forense, tais atos, por serem de menor complexidade,são efetuados por servidores comissionados ou por serventuários de secretaria. Todavia, em razão do já mencionado excesso de processos em trâmite, o número de servidores necessários para dar vazão aos processos em curso é por demais avantajado. 
A IA pode auxiliar na substituição das tarefas desempenhadas por estes servidores nos atos não decisórios.Uma vez que configuram medidas que permitem a marcha processual até o seu final, o desenvolvimento de robôs especializados na sua elaboração permitirá a simplificação de processos mecânicos e repetitivos, bem como evitando eventuais erros quando executados por humanos, cuja produtividade varia em razão da falta de foco ou por desatenção.

Acrescente-se que, quando consideramos apenas a fase executiva, é possível vislumbrar a IA nos atos de constrição, destacadamente em atos como o bloqueio de valores em conta corrente e em aplicações financeiras, cruzamento de dados nas hipóteses de grupos econômicos, o registro de gravame judiciais em bens, a indisponibilidade e restrição de circulação de automóveis e a pesquisa patrimonial - possíveis mediante acesso a sistemas de convênio entre os órgãos da Justiça e entes públicos de fiscalização, comoBacenJud, RenaJud e InfoJud - sendo estas às principais medidas para de satisfação do crédito e a efetivação da prestação jurisdicional. Atualmente esse processo é realizado de forma manual, porém com a IA será possível monitorar os serviços conveniados e realizar a consulta/bloqueio com maior assertividade e efetividade.

Os ganhos decorrentes de tal medida seriam consideráveis, não restritos ao tempo e efetividade jurisdicional, mas também à economia com as despesas de pessoal, permitindo-se liberar os serventuários da Justiça para realizar as demais atividades judiciárias, bem como dispensar aquela mão de obra excedente.

\section{3 - Atos Decisórios e o Juiz-Robô}

Maior dificuldade encontra-se na discussão sobre a possibilidade de realização de atos decisórios porum juiz-robô. Como visto, diante das características inerentes à própria programação dos algoritmos, que podem esconder vieses na seleção dos dados relevantes para construção da decisão judicial, não se pode partir da premissa de uma neutralidade da decisão judicial proferida por IA. Entretanto, a simples identificação de tais problemas não pode causar a desconsideração da tecnologia. Destacadamente quando se percebe que o serviço judiciário, a despeito dos esforços de seus integrantes, permanece ineficiente e dispendioso.

Até mesmo porque a própria imparcialidade do juiz humano foi - e ainda é questionada. Ora, exatamente para fiscalizar e controlar os eventuais vieses cognitivos que o legislador previu o art. 93, inc. IX da CF, bem como as situações nas quais estará ausente a fundamentação, nos exatos termos do art. $489, \S^{\circ}$, do CPC/2015. O juiz humano deve ser, como prevê o legislador, imparcial. 
A despeito de não existir disposição constitucional expressa determinando a sua imparcialidade, parece certo afirmar que tal característica do magistrado é imprescindível na construção do processo justo(NALINI, 2009, p. 66). Artur César de Souza (2017, p. 61) aponta quatro corolários da imparcialidade, a saber, a) imparcialidade como objetividade (ausência de influência de questões subjetivas, pessoais); b) imparcialidade como isenção (não intervenção do magistrado na relação jurídica processual civil ou penal); c) imparcialidade como transparência (as decisões judiciais não podem ser proferidas em segredo, mas de forma pública); e d) imparcialidade como neutralidade (posição distante e sem interesses do juiz na relação existente entre as partes).

Para os fins do presente artigo, melhor destaque merece a relação entre imparcialidade e neutralidade. Isso porque a noção de neutralidade é resultado da influência do pensamento liberal no processo (SOUZA, 2017, p. 62), destacadamente no contexto histórico do século XVIII, no qual pretendia-se retirar as influências políticas que subordinavam o Poder Judiciário. "A neutralidade caracterizava-se pelo distanciamento do Poder Judiciário em relação aos interesses das diferentes forças político-partidárias.” (SOUZA, 2017, p. 62). Partindo de tal perspectiva, a neutralidade é concebida em duas vertentes, sendo uma objetiva, direcionada ao Poder Judiciário e sua posição institucional de não participar dos embates políticos de determinada sociedade; e outra subjetiva, focada no magistrado, o qual deverá atuar sem qualquer indício de condução político partidário.

Entretanto, a neutralidade, na sua concepção clássica , enfrenta sérias críticas . Isto porque, considerando as características do comportamento humano , sempre haverá, no mínimo uma escolha ou ao menos uma predisposição para determinado posicionamento político. Assim sendo, torna-se humanamente impossível uma neutralidade absoluta pelos magistrados (PAMPLONA FILHO, 2001). Como sustenta Jose Renato Nalini (2015, p. 348), é necessária uma revisão na imparcialidade pois a neutralidade se perdeu. Logo, uma característica que não se pode exigir de um magistrado ou de qualquer outro indivíduo é a neutralidade.

Assim, como não se pode esperar uma neutralidade do magistrado humano, tampouco é legítimo esperar que o juiz-robô se comporte de forma isenta. Necessário, portanto, que a programação do algoritmo para elaboração de decisões judiciais seja elaborado em conformidade com os princípios previstos na Carta Magna.

Para aplicação da IA em tais parâmetros, necessário que os algoritmos sejam transparentes, com especial destaque para os data sets viciados, bem como a discriminação do algoritmo. Considerando que a sua aplicação pelo Poder Judiciário dependerá de desenvolvimento de ferramentas adequadas para a atividade jurisdicional, toda a programação 


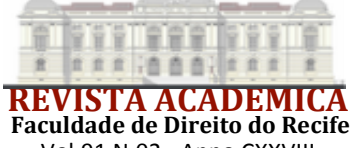

Faculdade de Direito do Recife

Vol.91 N.02 - Anno CXXVIII

deve ser aberta, para permitir o seu controle por órgãos externos e pela sociedade. Em especial, se tais ferramentas forem desenvolvidas por empresas privadas eventualmente contratadas pelo respectivo tribunal. É necessário perceber que empresas que atuam no ramo de tecnologia possuem interesses próprios (MOROZOV, 2018, p. 27-28), diversos daqueles buscados pelo Poder Público, de tal modo que a publicidade de todo o funcionamento da IA com função decisória deve ser requisito para validação.

No desenvolvimento da ferramenta que elaborará a decisão, tendo em vista o objetivo de extirpar, ou mesmo minimizara ocorrência dedata sets viciados, deverá existir uma equipe multidisciplinar, composta por juristas, desenvolvedores de sistemas, sociólogos, historiadores, dentre outros, que poderão contribuir para o controle dos dados e fiscalização dos resultados.

Isso porque a base de dados disponível para a construção da IA são as decisões do Poder Judiciário, que ainda carregam evidências de racismo, quando se verifica que negros são condenados com menores quantidades de entorpecentes (Agencia Publica, 2017), machismo, como na recusa dos magistrados de cumprirem o habeas corpus coletivo concedido pelo STF para conversão da prisão domiciliar às mães (MEGGIOLARO, 2018), desigualdade social, exemplificada pelo relatório World Justice Project (AGRAST;et. Al, 2015), que aponta a variável "discriminação no sistema criminal" tendo o Brasil como o $94^{\circ}$ pior dentre 101 países, em razão da menor probabilidade de condenação de réus com melhores condições econômicas, dentre outros problemas.Ou seja, é imprescindível considerar o problema da fonte dos inputs para o algoritmo.

Ainda, imprescindível que após o desenvolvimento seja a ferramenta testada em situações diversas, na tentativa de identificar as falhas na solução do caso em julgamento. Importante também que o resultado de tais testes seja apresentado e debatido pelas mais distintas áreas de conhecimento no objetivo de tornar o algoritmo mais preciso, sem opacidade ou discriminações.Por isto, entende-se que sejam realizados antes que qualquer decisão judicial realizada por juiz robô substitua os magistrados humanos. Conforme acima indicado, testes similares ao que a Suprema Corte dos EUA realizou - e ainda realiza -, servem de indicativo do caminho a ser trilhado.

Lado outro, e considerando as premissas outrora apresentadas, por se tratar de uma máquina, sua capacidade de aprendizado dependerá dos algoritmos desenvolvidos pelos programadores humanos. Atento à finalidade de evitar a discriminação pelo algoritmo, necessário definir os parâmetros legais para a sua utilização, assim como já ocorre na União Europeia e nos Estados Unidos. Em abril de 2019, os legisladores norte-americanos apresentaram um projeto de lei para regulamentar o uso da IA, inclusive em relação a decisões 
automatizadas. $\mathrm{O}$ intuito da norma é transmitir maior transparência e segurança aos cidadãos evitando situações como aquela ocorrida na Suprema Corte de Wisconsin. O projeto denominado de AlgorithmicAccountabilityAct determinaa auditoria de seus sistemas de Machine Learningpara casos de preconceito e discriminação, bem como exige que sejam tomadas medidas corretivas quando identificada falhas nas suas decisões (DE LUCA, 2019).

Por sua vez , a União Europeia pretende definir parâmetros legais para sua utilização conforme resolução de 12 de fevereiro de 2019, estabelece: "sobre uma política industrial europeia completa no domínio da inteligência artificial e da robótica :X. Considerando que a aprendizagem automáticatambém suscita desafios no que diz respeito à garantia da nãodiscriminação, ao processo equitativo, à transpa rência e à inteligibilidade dos processos decisórios" (EUROPARL, 2019). Todavia, isso não é uma unanimidade em todo o continente europeu, pois em março de 2019 o presidente da França, EMMANUEL MACRON, promulgou a lei 2019-222 que trata da programação judiciária do país e aproveitou para incluir a proibição da utilização de Inteligência Artificial na análise da jurisprudência francesa (CAMARGO, 2019).

Partindo de tais premissas, uma vez que a IA para realização de atos decisórios provoca desafios no que tange ao respeito a garantias como não discriminação, exigência a um processo equitativo e transparente, defende-seser imprescindível a sua regulação por legislação específica, estabelecendo critérios mínimos de desenvolvimento e controle da atividade de programação de IA para os Tribunais brasileiros, proporcionando uma maior segurança jurídica tanto aos operadores do Direito como para os jurisdicionados. Assim, parece certo afirmar que o debate em âmbito legislativo e, ao final, seja proposta uma legislação pertinente ao desenvolvimento e fiscalização dos algoritmos utilizados em órgãos públicos, com especial destaque para o Poder Judiciário.

Não obstante, é importante destacar que o uso da IA, mesmo sem a substituiçãointegral do juiz humano pelo juiz-robô, possibilitará uma maior uniformização nas decisões dos magistrados. Tendo em vista a sua capacidade de trabalhar com grandes quantidades de informações,haja vista as inúmeras decisões de mesmos tribunais em sentidos opostos, ocasionando milhares de recursos as instâncias superiores e, por consequência, elevando o custo de manutenção do Poder Judiciário. Considerando o sistema de precedentes adotado pelo CPC/15 (BRITO, 2016), a criação de uma ferramenta que auxilia o magistrado na elaboração da decisão em conformidade com o posicionamento adotado pelas Cortes Supremas (MARINONI, 2017), permite atingir de forma simplificada a finalidade de integridade e coerência da jurisprudência, preconizada pelo art. 926 do CPC/15. 
Com isso, possivelmente o número de recursos as instâncias superiores reduzirá, uma vez que a uniformidade será resguardada proporcionando maior coesão e segurança jurídica para os jurisdicionados.

\section{Considerações Finais}

É evidente que demandas em massa podem ser beneficiadas pelo emprego de robôs com IA. Incontroverso, ainda, que filtros, análises prévias e separação de documentos podem ser realizados por máquinas, sendo que estas funcionalidades se encontram disponíveis em nossos tribunais, como fora apresentado nesta pesquisa.

Porém, não podemos parar por aí, a evolução da IA é constante e quanto maior for sua base de consulta, melhor será sua acuracidade. A capacidade de analisar milhões de informações em segundos com extrema eficácia é enorme, algo impensável quando se comparado ao ser humano. Devido a isso, entendemos que a sua utilização promoverá aumento na produtividade dos servidores/juízes e auxiliará os tribunais na redução dos seus déficits, contribuindo de sobremaneira nos seus orçamentos e na redistribuição das funções para os servidores.

Naturalmente que as possibilidades indicadas nesta pesquisa não encerram as oportunidades trazidas pela aplicação da IA, porém, proporcionam uma excelente reflexão para os operadores do Direito e para as empresas de legaltechs. Procuram-se alternativas para o Poder Judiciário alcançar a tão esperada celeridade processual e, com certeza, com a IA poderemos reduzir vertiginosamente o cenário trágico que assola este órgão estatal, uma vez que sua capacidade de produção potencializará a reorganizaçãode todo o Poder Judiciário.

Desta forma, considerando o respeito às leis brasileiras estabelecidas em nossa Constituição Federal, será possível estabelecer critérios legais para que robôs desempenhem funções,prolatem decisões e despachos, permitindo economia financeira e processual, restabelecendo o prestígio na justiça.

\section{Referências}

AGRAST, M. D.;BOTERO, J. C.; MARTINEZ, J.; PONCE, A.; PRATT, C. The World Justice Project: Rule of Law Index 2015. World Justice Project. Disponível em:

https://worldjusticeproject.org/sites/default/files/roli_2015_0.pdf. Acesso em: 04 abr. 2020. 
ASIMOV, Isaac. The Toronto Star. Edição de 31/12/1983. Disponível em:

https://www.thestar.com/news/world/2018/12/27/35-years-ago-isaac-asimov-was-asked-by-thestar-to-predict-the-world-of-2019-here-is-what-he-wrote.html. Acesso em: 02 jan. 2020.

BOURDIEU, Pierre. A dominação masculina: a condição feminina e a violência simbólica. Rio de Janeiro: BestBolso, 2014.

BRASIL. Superior Tribunal do Trabalho. Inteligência artificial traz melhorias inovadoras para tramitação de processos no TST. Disponível em: https://www.ab2l.org.br/inteligenciaartificial-traz-melhorias-inovadoras-para-tramitacao-de-processos-no-tst/. Acesso em: 26 maio 2019.

BRITO, Thiago Carlos de Souza. Gerenciamento dos processos judiciais: Estudo Comparado dos Poderes e Atuação do Juiz na Inglaterra, nos Estados Unidos e no Brasil. Dissertação (Mestrado) - Universidade Federal de Minas Gerais, 2013.

BRITO, Thiago Carlos de Souza. Crítica aos recursos repetitivos de acordo com a teoria dos precedentes e a função jurisdicional. Revista da Faculdade de Direito da UFRGS. n. 35, p. 252-267, dez. 2016.

CAPPELLETTI, Mauro; GARTH, Bryan. Acesso à justiça. Porto Alegre: Sergio Antonio Fabris Editora, 2002.

CARVALHO, Claudia. A inteligência artificial na Justiça dos EUA e o Direito Penal brasileiro. Disponível em: https://www.ab2l.org.br/inteligencia-artificial-na-justica-dos-eua-e-odireito-penal-brasileiro/. Acesso em: 25 maio 2019

CONSELHO NACIONAL DE JUSTIÇA (Brasil).Relatório Justiça em Números 2019, p. 79. Disponível em: http://www.cnj.jus.br/pesquisas-judiciarias/justicaemnumeros/2016-10-21-13-1304/pj-justica-em-numeros. Acesso em: 18 set.2019.

COPPIN, Ben. Inteligência Artificial. Rio de Janeiro: LTC, 2010.

DE LUCA, Cristina. Americanos dão o primeiro passo para regulamentar a Inteligência Artificial. Disponível em: https://porta23.blogosfera.uol.com.br/2019/04/12/americanos-dao-oprimeiro-passo-para-regulamentar-a-inteligencia-artificiall. Acesso em: 26 maio 2019.

D’ALMEIDA, André Correa; BREHM, Katie; HIRABAYASHI, Momori; LANGEVIN, Clara; MUÑOZCANO, Bernardo Rivera; SEKIZAWA, Katsumi; ZHU, Jiayi. Futuro da IA no sistema judiciário brasileiro: mapeamento, integração e governança. New York, 2020.

DOMENICI, Thiago; BARCELOS, Iuri. Negros são mais condenados por tráfico e com menos drogas em São Paulo. Agência pública. Disponível em:

https://apublica.org/2019/05/negros-sao-mais-condenados-por-trafico-e-com-menos-drogas-emsao-paulo/. Acessoem: 04 abr. 2020.

EUROPARL, Disponível em: http://www.europarl.europa.eu/doceo/document/TA-8-20190081_PT.html?redirect. Acesso em: 18 ago.2019. 
FERRARI, Isabela; BECKER, Daniel; WOLKART, Erick Navarro. ArbitrumExMachina: panorama, riscos e a necessidade de regulação das decisões informadas por algoritmos. Revista dos Tribunais, v. 995, p. 635-655, set. 2018.

FORSTER, João. Pode o “juiz natural” ser uma máquina? Disponível em: http://sisbib.emnuvens.com.br/direitosegarantias/article/view/1631. Acesso em: 22 set.2019

LIMA, Juliana Domingos de. Por que tantos assistentes virtuais têm nome de mulher.

Disponível em: https://www.nexojornal.com.br/expresso/2018/12/04/Por-que-tantos-assistentesvirtuais-têm-nome-de-mulher. Acesso em: 06 out.2019

LOPES, Camila. O que é ADR (alternative dispute resolution) e ODR (online dispute resolution)? Disponível em: https://legaltechnobrasil.com.br/noticias/10471-o-que-e-adralternative-dispute-resolution-e-odr-online-dispute-resolution/. Acesso em: 25 out.2019.

MARINONI, Luiz Guilherme. Julgamento nas cortes supremas: precedente e decisão do recurso diante do novo CPC. 2.ed.São Paulo: RT, 2017.

MARQUES, Ricardo Dalmaso. A resolução de disputas online: do comércio eletrônico ao seu efeito transformador sobre o conceito e a prática do acesso à justiça. Revista de Direito e Novas Tecnologias, São Paulo, v.5, out./dez. 2019.

MEGGIOLARO, Daniella. O machismo no judiciário. Migralhas de Peso. Disponível em: https://www.migalhas.com.br/depeso/289230/o-machismo-no-judiciario. Acesso em: 10 abr. 2020.

MOROZOV, Evgeny. Big tech: a ascensão dos dados e a morte da política. São Paulo: Ubu, 2017.

NALINI, José Renato. Ética na magistratura. São Paulo: RT, 2009.

NALINI, José Renato. A rebelião da toga. 3. ed. São Paulo: RT, 2015.

NUNES, Dierle; MARQUES, Ana Luiza Pinto Coelho. Inteligência artificial e direito processual: vieses algoritmos e os riscos de atribuição de função decisória às máquinas.Revista de Processo, v.285, p. 421-447, nov. 2018.

PAMPLONA FILHO, Rodolfo. O mito da neutralidade do juiz como elemento de seu papel social. Disponível em: https://jus.com.br/artigos/2052/o-mito-da-neutralidade-do-juiz-comoelemento-de-seu-papel-social. Acesso em: 16 jun.2019

PORTO JÚNIOR, Odélio. Como a inteligência artificial pode afetar os tribunais? Disponível em: http://irisbh.com.br/como-a-inteligencia-artificial-pode-afetar-os-tribunais/. Acesso em: 06 out.2019

ROS, Luciano da.O custo da Justiça no Brasil: uma análise comparativa exploratória. Observatório de elites políticas e sociais do Brasil, Curitiba, v. 2, n. 9, 2015.

RUSSEL, Stuart J. Inteligência artificial. Rio de Janeiro: Elsevier, 2013. 


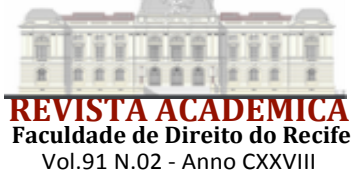

SOUZA, Artur César. Imparcialidade do juiz: uma leitura constitucional de sua concepção dogmática. Revista de Processo, v. 269, p. 59-88, jul. 2017.

TAURION, Cezar. Revista do TCU: as inovações tecnológicas na fiscalização. Disponível em: https://revista.tcu.gov.br/ojs/index.php/RTCU/issue/download/68/101. Acesso em: 26 maio 2019.

TEIXEIRA, Matheus. STF investe em inteligência artificial para dar celeridade a processos. Disponível em: https://www.ab2l.org.br/stf-investe-em-inteligencia-artificial-para-darceleridade-a-processos/. Acesso em: 28 maio 2019.

THEODORO JÚNIOR, Humberto. Curso de Direito Processual Civil. 56. ed. Rio de Janeiro: Forense, 2015.v. 1.

VILLAN, Cédric. Donner uns sens à li'intelligence artificielle: pour une stratégie nationale et européenne. Disponível em: https://www.aiforhumanity.fr. Acesso em: 12 jul.2019.

WOLKART, Erik Navarro. Análise Econômica do Processo Civil. São Paulo: RT, 2018.

ZANETI JÚNIOR, Hermes; CABRAL, Antônio do Passo. Entidades de infraestrutura específica para resolução de conflitos coletivos: as claimsresolutionsfacilitiese sua aplicabilidade no Brasil.Revista dos Tribunais, v. 287, p. 445-483, jan. 2019. 